The investigations herein reported from Vanderbilt University were supported in part by grants from the National Vitamin Foundation, the U.S. Public Health Service, and the Nutrition Foundation, Inc.

\title{
REFERENCES
}

Beam, A. S. (1949). A study of serum ascorbic acid in the guinea pig. Thesis submitted to the Graduate Faculty of Vanderbilt University, Nashville, Tennessee.

Dawson, J. R. Jr., Woodruff, C. W. \& Darby, W. J. (I950). Proc. Soc. exp. Biol., N.Y., 73, 646.

Dyke, S. C., Della Vida, B. L. \& Delikat, E. (1942). Lancet, 243, 278.

Gabuzda, G. J. Jr., Phillips, G. B., Schilling, R. F. \& Davidson, C. S. (1952). F. clin. Invest. 31, 756.

Levine, S. Z., Barnett, H. L., Bierman, C. W. \& McNamara, H. (1951). Science, rr3, 3 II.

Levine, S. Z., Gordon, H. H. \& Marples, E. (194I). F. clin. Invest. 20, 209.

Levine, S. Z., Marples, E. \& Gordon, H. H. (194I). F. clin. Invest. 20, 199.

Morris, J. E., Harpur, E. R. \& Goldbloom, A. (1950). F. clin. Invest. 29, 325.

Nichol, C. A. \& Welch, A. D. (1950). Proc. Soc. $\exp$. Biol., N.Y., 74, 52.

Nitowsky, H. M., Govan, C. D. Jr. \& Gordon, H. H. (1953). Amer. F. Dis. Child. 85, 462.

Painter, H. A. \& Zilva, S. S. (1947). Biochem. F. 41, 5 I I.

Rienits, K. G. (1950). F. biol. Chem. 182, I r.

Rodney, G., Swendseid, M. E. \& Swanson, A. L. (1947). F. biol. Chem. 168, 395.

Rodney, G., Swendseid, M. E. \& Swanson, A. L. (1949). F. biol. Chem. 179, 19.

Rogers, W. F. Jr. \& Gardner, F. (1949), F. clin. Invest. 28, 806.

Salmon, R. J. \& May, C. D. (1950). F. Lab. clin. med. 36, $59 \mathrm{I}$.

Salmon, R. J. \& May, C. D. (r953). F. Lab. clin. Med. 4r, 376.

Sealock, R. R. (1942). $f$. biol. Chem. 146, 503.

Sealock, R. R. \& Lepow, J. P. (1948). F. biol. Chem. 174, 763.

Sealock, R. R. \& Silberstein, H. E. (1940). $\mathcal{F}$. biol. Chem. 135, 25 r.

Swendseid, M. E., Wandruff, B. \& Bethell, F. H. (1947a). F. Lab. clin. Med. 32, I242.

Swendseid, M. E., Wandruff, B. \& Bethell, F. H. (1947b). F. Lab. clin. Med. 32, 1248.

Woodruff, C. W. (1950). F. Lab. clin. Med. 36, 640 .

Woodruff, C. W., Cherrington, M. E., Stockell, A. K. \& Darby, W. J. (1949). F. biol. Chem. 178, 86r. Woodruff, C. W. \& Darby, W. J. (r948). F. biol. Chem. 172, 85 I.

Woodruff, C. W., Peterson, J. C. \& Darby, W. J. (1951). Proc. Soc. exp. Biol., N.Y., 77, 16.

Woolf, L. I. \& Edmunds, M. E. (1950). Biochem. F. 47, 630.

\section{Synthesis of L-Ascorbic Acid in Plants and Animals}

\author{
By F. A. IsHerwoon, Low Temperature Station for Research in Biochemistry and \\ Biophysics, University of Cambridge and Department of Scientific and Industrial \\ Research
}

The chemical synthesis of L-ascorbic acid from D-galactose, by Haworth, Hirst and co-workers in 1932 , stimulated speculation as to whether the biological synthesis of L-ascorbic acid proceeds along similar lines (Haworth \& Hirst, 1933). The common occurrence of sugars in both plants and animals, and the fact that $\mathrm{L}-$ ascorbic acid is closely related to a sugar, L-gulose, tended to support this idea. Two 
particular pieces of evidence may be cited which suggest that a hexose is the precursor. In plants the overall conversion of sugars (D-glucose, D-fructose and D-mannose) into L-ascorbic acid has been shown in cotyledonless pea seedlings by Ray (1934) and, in the rat, Professor C. G. King and his colleagues have shown that ${ }^{14} \mathrm{C} \mathrm{D}$-glucose labelled uniformly in all positions caused the excretion in the urine of L-ascorbic acid which was also labelled uniformly in all positions (Jackel, Mosbach, Burns \& King, 1950). No clue had, however, been obtained as to the series of changes by which the hexose was transformed into L-ascorbic acid. The investigations to be described in this and the following paper (Mapson, 1953) were directed towards establishing the nature of the hexose precursor and elucidating the mechanism by which the hexose is transformed into L-ascorbic acid. The general plan was to assume that the hexose precursor was probably D-glucose, and then to imagine the transformation to $\mathrm{L}$-ascorbic acid in terms of a series of known chemical and biochemical reactions. The main emphasis was on the changes in configuration necessary (see p. 337) for the sugar which is a member of the D-series of sugars to be transformed into L-ascorbic acid which is closely related to a member of the L-series of sugars.

Each scheme was tested by adding the compounds postulated as intermediates to germinating cress seedlings or, with rats, giving them by subcutaneous injection. The increase in the amount of L-ascorbic acid present in the treated seedling as compared with those grown in water indicated whether the compound could act as a precursor. With rats, the amount of L-ascorbic acid in the urine was measured.

An important technical point was that all compounds described in the schemes quoted on p. 337 as sugar acids, were added to the cress seedlings or injected into the rats as lactones or esters. Under experimental conditions it was not possible to test the free acids because organic compounds that are ionized in solution do not readily penetrate the cell wall. Lactones and esters, being non-ionized, penetrate readily and then give the free acid inside the cell; lactones are preferable because they are internal esters and are free from the criticism that a 'foreign' alcohol is introduced into the cell which might affect the synthesis to the L-ascorbic acid.

For convenience in presentation, the various suggested sequences of reactions have been grouped under two main headings.

Indirect conversion (i.e. the carbon chain is broken and then reformed) involves the breakdown of the D-glucose via fructose diphosphate to the triose phosphates and the conversion of these into other three-carbon compounds which then combine to give L-ascorbic acid. Assuming that this occurs, two main types of condensation reaction can be suggested.

The first is based on an aldol condensation between L-glyceraldehyde and hydroxypyruvic acid (which might be catalysed by an enzyme similar in function to the aldolase of animal and plant tissue) to give 2-keto-L-gulonic acid which is then transformed into L-ascorbic acid.

The second is based on an acyloin reaction between tartronic semialdehyde and 
L-glyceraldehyde to give 3 -keto-L-gulonic acid which is then transformed into Lascorbic acid.

Direct conversion (i.e. without breaking the carbon chain of the D-glucose) involves either the inversion of the configuration of the groups on carbon atom 5 , or an inversion of all the asymmetric carbons by transferring the aldehyde or potential aldehyde group from carbon $\mathrm{I}$ to the terminal atom of the carbon chain.

The inversion of the groups attached to carbon atom 5 could occur through the intermediate formation of a 5 -keto-compound, as in the following scheme:

D-glucose $\longrightarrow$ D-gluconic acid $\longrightarrow$ 5-keto-D-gluconic acid $\longrightarrow$ L-idonic acid $\longrightarrow$ L-ascorbic acid.

The possibility of inverting all the asymmetric carbon atoms by transferring the potential aldehyde group from carbon $I$ to the terminal atom of the carbon chain is the basis of the two following schemes:

$$
\begin{aligned}
& \text { D-glucose } \longrightarrow \text { D-sorbitol } \longrightarrow \text { L-sorbose } \longrightarrow \text { 2-keto-L-gulonic acid } \longrightarrow \\
& \text { L-ascorbic acid }
\end{aligned}
$$

and

D-glucose $\longrightarrow$ D-glucuronic acid $\longrightarrow$ L-gulonic acid $\longrightarrow$ L-ascorbic acid.

The first of these is very similar to the sequence of reactions used for the commercial manufacture of L-ascorbic acid. The second has been shown, in actuality, to be substantially the pathway by which D-glucose is transformed into L-ascorbic acid.

The experimental facts are as follows. The $\gamma$-lactones of D-glucuronic and Lgulonic acids when added to cress seedlings or injected into rats, were found to be transformed into L-ascorbic acid. D-galacturonic acid methyl ester and L-galactono$\gamma$-lactone behave similarly. No other sugar-acid $\gamma$-lactone yielded L-ascorbic acid when tested in the same way, although all the sugar-acid $\gamma$-lactones, both $D$ - and $L-$, were examined, except those of L-allonic and L-altronic acids.

These facts suggest that two analogous sequences of reactions can take place as indicated in the accompanying schemes. A fundamental feature of both schemes is the change, at the second step, from the $D$ - to the $L$ - series with inversion of the whole molecule: it is significant that Professor C. G. King and his colleagues have just shown that, in the rat, D-glucose labelled with ${ }^{14} \mathrm{C}$ at position I produces $\mathrm{L}$ ascorbic acid labelled mainly at position 6 (Harowitz, Doerschuk \& King, 1952).

During the investigation it was found that $\mathrm{D}$-araboascorbic acid (the configuration of which differs from that of L-ascorbic acid only at carbon atom 5) was produced from two of the lactones, in the rat from D-mannose- $\gamma$-lactone only and in cress seedlings from D-altrono- $\gamma$-lactone only.

The other mechanisms briefly described earlier whereby hexoses might be transformed to L-ascorbic acid, involving L-glyceraldehyde, L-sorbose, D-sorbitol and $\mathrm{D}$-gluconic acid, have not been found in cress seedlings or in the rat.

The discovery of a series of reactions that describe in broad outline the pathway by which hexose sugars are converted into L-ascorbic acid is important because it opens up the subject for rapid advances on the enzymic side, though it is possible 


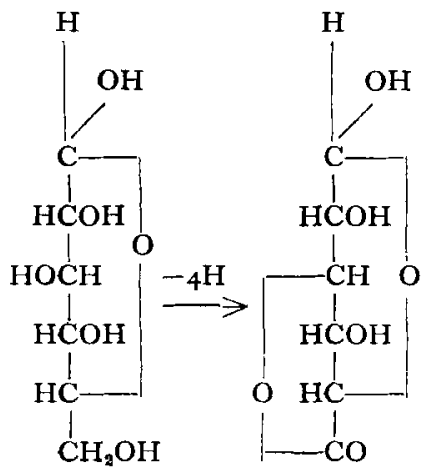

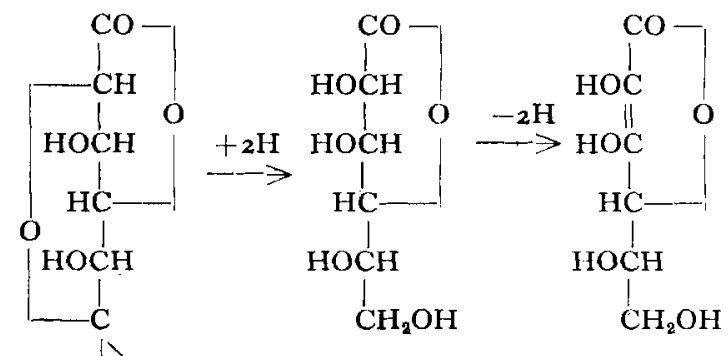<smiles>OC[C@H](O)[C@H](O)[C@H](O)[C@H](O)CO</smiles>

$\mathrm{H}$<smiles>O=C(O)C(O)C(O)C(O)C(O)CO</smiles><smiles>O=C(O)C(O)C(O)C(O)C(O)CO</smiles>

D-galactose

\footnotetext{
Alternative forms of writing $D-$ galacturonic acid to show inversion of configuration
}<smiles>O=C(O)C1OCOCC1C(O)CO</smiles><smiles>O=C1COCC(C(O)CO)C(O)C1</smiles>

L-galactono- $\gamma$-lactone
I.ascorbic acid

that the reactions involved in the transformation may not be so simple as in the above scheme.

Mapson (1953) discusses the enzymic mechanism by which plant mitochondria produce L-ascorbic acid from L-galactono- $\gamma$-lactone; it has, further, been shown that mitochondria from rat liver will catalyse the transformation both of L-gulonoand L-galactono- $\gamma$-lactones to L-ascorbic acid.

The work described in this paper was carried out as part of the programme of the Food Investigation Organization of the Department of Scientific and Industrial Research. 
Haworth, W. N. \& Hirst, E. L. (1933). Chem. $\$$ Ind. 52, 645.

Harowitz, H. H., Doerschuk, A. P. \& King, C. G. (1952). F. biol. Chem. 199, 193.

Jackel, S. S., Mosbach, E. H., Burns, J. J. \& King, C. G. (1950). F. biol. Chem. 186, 569.

Mapson, L. W. (1953). Proc. Nutr. Soc. 12, 339.

Ray, S. N. (1934). Biochem. F 28, 996.

\section{The Enzymic Conversion of L-Galactono- $\gamma$-Lactone to L-Ascorbic Acid by Plant Mitochondria}

By L. W. Mapson, Low Temperature Station for Research in Biochemistry and Biophysics, University of Cambridge and Department of Scientific and Industrial Research

Belief that the synthesis of L-ascorbic acid in vivo does in fact proceed via the following routes:D-glucose $\rightarrow$ D-glucurono- $\gamma$-lactone $\rightarrow$ L-gulono- $\gamma$-lactone $\rightarrow$ L-ascorbic acid D-galactose $\longrightarrow$ D-galacturonic methyl ester $\longrightarrow$ L-galactono- $\gamma$-lactone $\longrightarrow$ L-ascorbic acid

would be greatly strengthened if it were shown that any of these steps could be carried out by enzyme preparations in vitro.

Our initial investigations were therefore planned to determine whether an enzyme extract could be obtained that would catalyse the last stage in this sequence of reactions, i.e. would convert either L-gulono- $\gamma$-lactone or L-galactono- $\gamma$-lactone to L-ascorbic acid. Germinating seedlings, in which L-ascorbic acid forms rapidly, were used as raw materials, extracts being prepared from them in the early stages of germination when those enzymes that can oxidize ascorbic acid are either absent or show lower activities than in the more fully developed plant.

Success was achieved with extracts in which the mitochondria (cytoplasmic particles) of the cell were preserved intact. Mitochondria prepared from partially germinated pea seedlings were able to convert L-galactono- $\gamma$-lactone rapidly to L-ascorbic acid, but could not effect the corresponding conversion of L-gulono- $\gamma$ lactone to L-ascorbic acid. The reaction proceeded smoothly until approximately $40 \%$ of the lactone had been transformed into L-ascorbic acid, and then ceased, but began again if an additional quantity of the lactone was added. The disappearance of the lactone, apart from that portion converted to L-ascorbic acid, was shown to be due to its conversion into the free galactonic acid, a reaction which proceeds simultaneously with the enzymically catalysed formation of $\mathrm{L}$-ascorbic acid. Since galactonic acid is not itself converted to L-ascorbic acid, this reaction decreases the yield of L-ascorbic acid obtained from the $\gamma$-lactone. 